\title{
Pediatric Resident Knowledge, Confidence, and Experience in Transitioning Youth with Special Healthcare Needs
}

\author{
Kerri Weeks, M.D., Kari Harris, M.D., Ragneel R. Bijjula, M.D.,
}

Carolyn R. Ahlers-Schmidt, Ph.D.

University of Kansas School of Medicine-Wichita

Department of Pediatrics, Wichita KS

\begin{abstract}
Background. The transition from pediatric to adult healthcare is vital to the $17 \%$ of adolescents with special healthcare needs (SHCN). Barriers to successful transition exist. The purpose of this study was to assess the baseline knowledge, confidence, and experience of pediatric residents in our state on transitioning adolescents with SHCN from pediatric to adult-oriented health care.

Methods. An anonymous, voluntary, self-report survey was distributed electronically via Survey Monkey $_{\circledast}$ to 2011-2012 pediatric residents in the state of Kansas $(\mathrm{n}=39)$.

Results. Of 39 pediatric residents, 21 (54\%) completed the survey. Most (71\%) had two or fewer adolescents with SHCN on their patient panel. Overall, the majority categorized their knowledge (71\%) and experience (81\%) transitioning adolescents with SHCN as minimal or very minimal.

Conclusions. Pediatric residents report a general lack of knowledge, confidence, and experience in transitioning youth with SHCN. Additional training opportunities are needed to overcome the barriers in successful transition planning.
\end{abstract}

KS J Med 2014; 7(2):46-49.

\section{Introduction}

Over the past two decades, health care providers, researchers, and government agencies have concentrated efforts on improving health care and related services to youth with special health care needs (SHCN). According to the Maternal Child Health Bureau, ${ }^{1}$ children with SHCN are those who "have or are at increased risk for a chronic physical, developmental, behavioral, or emotional condition and who require health and related services of a type or amount beyond that required by children generally." This definition is based on the degree of health care utilization rather than disease classification and encompasses children whose conditions vary in severity, including those with and without developmental impairment and physical limitations. These youth are particularly vulnerable in terms of their reliance on uninterrupted medical care for their health and welfare. Thus, addressing gaps in access and quality of care for this population is essential. $^{2}$

Transitions are expected and part of healthy development across the lifespan. The transition from pediatric to adult healthcare is an important milestone for all adolescents, but this process is vital to the $17 \%$ of adolescents with SHCN. ${ }^{3}$ Transitioning youth with SHCN encompasses a dynamic, patient-centered process that seeks to maximize functioning and potential as youth move from childhood to adulthood. ${ }^{4}$

The purpose of this study was to assess the baseline knowledge, confidence, and experience of pediatric residents in Kansas on transitioning adolescents with SHCN from pediatric to adult-oriented health care.

\section{Methods}

An anonymous, voluntary survey was distributed electronically via Survey Monkey $_{\circledast}$ to 2011-2012 pediatric residents 
in the state of Kansas $(n=39)$. Pediatric residencies in Kansas vary in geographic location and resource availability. This was a self-report survey regarding pediatric resident knowledge, confidence, and experiences in transitioning youth with SHCN. For initial nonresponders, two reminders were sent electronically. Prior to distribution, the survey was reviewed by a panel of 15 experts on transition from around the United States. These experts voluntarily reviewed the survey for face validity through an email list serve focused on healthcare transition. The survey also was reviewed by two recent pediatric residency graduates from our institution for clarity.

All data were managed using the Statistical Package for the Social Sciences (SPSS version 17.0; Chicago, IL). The study was approved by the university's institutional review board.

\section{Results}

Of 39 pediatric residents, 21 (54\%) completed the survey. All were in programs with less than 30 residents. Most pediatric residents (71\%) had two or fewer adolescents with SHCN on their patient panel; $43 \%$ reported they were uncomfortable providing primary care for youth with SHCN. In addition, the majority categorized their overall knowledge of (71\%) and experience (81\%) transitioning as minimal or very minimal. No resident rated knowledge or experience above the moderate level.

Familiarity with the process of transitioning varied (see Table 1). Only 14\% of residents report attending a training session or lecture on transition. However, for future training, the majority of the group (85\%) preferred didactic training sessions to online teaching. One resident stated, "This is a very important topic. I would like to receive more information/education during residency training.” Ultimately, 55\% responded that they rarely or never discuss the process of transition with families.

Table 1. Resident exposure and experience transitioning youth with SHCN by year.

\begin{tabular}{|l|c|c|c|}
\hline \multirow{2}{*}{} & \multicolumn{3}{|c|}{ Postgraduate Year } \\
\cline { 2 - 4 } & $1^{\text {st }}$ & $2^{\text {nd }}$ & $3^{\text {rd }}$ \\
\hline $\begin{array}{l}\text { I have heard about } \\
\text { transitioning during } \\
\text { my residency. }\end{array}$ & $\begin{array}{c}43 \% \\
(4 / 7)\end{array}$ & $\begin{array}{c}86 \% \\
(6 / 7)\end{array}$ & $\begin{array}{c}86 \% \\
(6 / 7)\end{array}$ \\
\hline $\begin{array}{l}\text { I have read } \\
\text { information about } \\
\text { transitioning during } \\
\text { my residency. }\end{array}$ & $\begin{array}{l}57 \% \\
(4 / 7)\end{array}$ & $\begin{array}{c}57 \% \\
(4 / 7)\end{array}$ & $\begin{array}{c}60 \% \\
(3 / 5)\end{array}$ \\
\hline $\begin{array}{l}\text { I have attended a } \\
\text { lecture/training } \\
\text { session focused on } \\
\text { transition. }\end{array}$ & $\begin{array}{l}33 \% \\
(2 / 6)\end{array}$ & $\begin{array}{c}(0 \% / 7) \\
(1 / 5)\end{array}$ \\
\hline $\begin{array}{l}\text { I am familiar with } \\
\text { standardized } \\
\text { transitioning } \\
\text { resources and tools. }\end{array}$ & $\begin{array}{l}17 \% \\
(1 / 6)\end{array}$ & $\begin{array}{c}(0 \% / 7) \\
(1 / 5)\end{array}$ \\
\hline $\begin{array}{l}\text { I am familiar with } \\
\text { adult health care } \\
\text { providers and } \\
\text { resources in my } \\
\text { community. }\end{array}$ & $\begin{array}{l}33 \% \\
\text { I have assisted a } \\
\text { patient with } \\
\text { transition in my } \\
\text { patient panel/ } \\
\text { continuity clinic. }\end{array}$ & $\begin{array}{l}(2 / 6) \\
(3 / 7)\end{array}$ & $(1 / 5)$ \\
\hline
\end{tabular}

*Denominators may vary due to missing responses.

\section{Discussion}

The importance of transition planning and support was highlighted in a foundational joint consensus statement released in 2002 by the American Academy of Pediatrics (AAP), American Academy of Family Physicians (AAFP), and the American College of Physicians (ACP). ${ }^{4}$ This statement was created to ensure that by 
2010 all physicians who provide primary and subspecialty care to youth with SHCN appreciate the need for transition, have knowledge and skills to identify when transitioning support is indicated, and have the ability to facilitate the process. One critical step outlined in this policy advises the incorporation of core transitioning knowledge and skill into resident education and physician certification.

Despite great efforts, in the 2011 clinical report published by the same organizations, authors cited only limited progress has been documented by outcomes research. ${ }^{5}$ Lack of physician training and comfort have been cited as major barriers to effective transitioning. ${ }^{3,6}$ According to a 2009 survey conducted by the AAP, ${ }^{3}$ less than half of pediatricians routinely offer adolescent patients with SHCN support services to transition to adult healthcare. Multiple barriers were cited in the study, including lack of knowledge about community resources for young adults with SHCN (39\%), insufficient time for staff to provide transition services (36\%), and lack of skills in transition planning (34\%).

Currently, there are no known published studies that have looked specifically at pediatric resident knowledge, confidence, or experience in transitioning. However, Patel and $\mathrm{O}^{\prime} \mathrm{Hare}^{7}$ surveyed pediatric and internal medicine residents to assess their training experiences and comfort treating an array of chronic childhood illnesses in the primary care setting. For children with chronic diseases (including cerebral palsy, Down's syndrome, cystic fibrosis, diabetes, and spina bifida), pediatric residents reported that they were more comfortable with inpatient management versus outpatient (primary care) management of these children.

In our study, residents reported little experience providing ongoing primary care for adolescents with SHCN. This lack of opportunity to follow youth with SHCN in the outpatient environment, combined with barriers of insufficient time and resources cited by pediatricians, ${ }^{3}$ may prevent pediatric residents from gaining the skill and confidence needed to successfully transition these youth.

Study limitations included a small population of pediatric residents in Kansas, self-report nature of surveys, and lack of quantitative data to support the findings. A larger, cross section of residents from across the US might yield different results. We recognized that family practice and internal medicine residents also provide care for youth with SHCN and play a role in transitioning. Pediatric residents, however, have a unique role in transitioning and transferring care. Therefore, we focused our study on this population. Inclusion of other providers may have yielded different or additional information.

\section{Conclusions}

Pediatric residents in Kansas have a general lack of knowledge, confidence, and experience in transitioning youth with SHCN. Barriers to successful transitioning exist. Additional educational opportunities through didactics and patient care experience are needed in this area. Training on transitioning must be integrated into resident education. Pediatric faculty should use this information when developing pediatric resident curricula. 


\section{References}

${ }^{1}$ McPherson M, Arango P, Fox H, et al. A new definition of children with special health care needs. Pediatrics 1998; 102(1 Pt 1):137-140. PMID: 9714637.

2 Lotstein DS, McPherson M, Strickland B, Newacheck PW. Transition planning for youth with special health care needs: Results from the National Survey of Children with Special Health Care Needs. Pediatrics 2005; 115(6):1562-1568. PMID: 15930217.

3 AAP Department of Research. Survey: Transition services lacking for teens with special needs. AAP News 2009; 30;12.

4 American Academy of Pediatrics; American Academy of Family Physicians; American College of Physicians-American Society of Internal Medicine. A consensus statement on health care transitions for young adults with special health care needs. Pediatrics 2002; 110(6 Pt 2):13041306. PMID: 12456949.

5 American Academy of Pediatrics, American Academy of Family Physicians,
American College of Physicians, Transitions Clinical Report Authoring Group, Cooley WC, Sageman PJ. Supporting the health care transition from adolescence to adulthood in the medical home. Pediatrics 2011; 128(1):182-200. PMID: 21708806.

${ }^{6}$ Okumura MJ, Heisler M, Davis MM, Cabana MD, Demonner S, Kerr EA. Comfort of general internists and general pediatricians in providing care for young adults with chronic illnesses of childhood. J Gen Intern Med 2008; 23(10):16211627. PMID: 18661191.

7 Patel M, O’Hare K. Residency training in transition of youth with childhood-onset chronic disease. Pediatrics 2010; 126 (Suppl 3):S190-S193. PMID: 21123485.

Keywords: adolescent, health transition, continuity of patient care, health services needs and demand, graduate medical education 